\title{
Aversive memory reactivation engages in the amygdala only some neurotransmitters involved in consolidation
}

\author{
Corrado Bucherelli, ${ }^{1}$ Elisabetta Baldi, ${ }^{1}$ Chiara Mariottini, ${ }^{1}$ Maria Beatrice Passani, ${ }^{2}$ and \\ Patrizio Blandina ${ }^{2,3}$ \\ ${ }^{1}$ Dipartimento di Scienze Fisiologiche, Universitá di Firenze, 50134 Firenze, Italy; ${ }^{2}$ Dipartimento di Farmacologia Preclinica e \\ Clinica, Universitá di Firenze, 50139 Firenze, Italy
}

\begin{abstract}
Consolidation refers to item stabilization in long-term memory. Retrieval renders a consolidated memory sensitive, and a "reconsolidation" process has been hypothesized to keep the original memory persistent. Some authors could not detect this phenomenon. Here we show that retrieved contextual fear memory is vulnerable to amnesic treatments and that the amygdala is critically involved. Cholinergic and histaminergic systems seem to modulate only consolidation, whereas cannabinoids are involved in both consolidation and reactivation. The lability of retrieved memory affords opportunities to treat disorders such as phobias, post-traumatic stress, or chronic pain, and these results help searching for appropriate therapeutic targets.
\end{abstract}

Memory of newly acquired information initially persists in a labile state and can be disrupted by several factors before becoming resilient to disruption and stable for long-term storage through a process named consolidation (McGaugh 2000). Yet, evidence suggests that consolidated memory is not permanent, for retrieval may return it to a sensitive state (Misanin et al. 1968; Bucherelli and Tassoni 1992; Nader et al. 2000). Another consolidation process that renders the original memory persistent, referred to as "reconsolidation," has been hypothesized (Sara 2000). However, results appear conflicting, and whether established memories, once recalled, require "reconsolidation" to persist is controversial (Millin et al. 2001; Biedenkapp and Rudy 2004; Cammarota et al. 2004; Dudai and Eisenberg 2004). Indeed, although the protein-synthesis inhibitor anisomycin impairs memory when given after retrieval (Nader et al. 2000), this amnesia reverses with time (Vianna et al. 2001; Lattal and Abel 2004; Power et al. 2006). Hence, a temporary deficit argues against the "reconsolidation" hypothesis (Rudy et al. 2006). To unravel this controversy, much effort has focused on determining whether reactivation and consolidation share the same mechanisms (McGaugh 2004; Alberini 2005; Nader et al. 2005).

Contextual fear conditioning is a paradigm to study emotional memory. In this test, consolidation follows the presentation of an unconditioned stimulus (US), e.g., an electrical foot shock, which becomes associated with the environment where it is administered (training context, TC). Trace reactivation is presumably elicited by the re-exposure to TC alone (Nader 2003). Nonoverlapping mechanisms between consolidation and reactivation have been proposed. In the hippocampus, consolidation depends on BDNF, but not on Zif268 expression, whereas reactivation requires Zif268, but not BDNF (Lee et al. 2004) and engages only a subset of consolidation-induced, immediate-early genes (von Hertzen and Giese 2005). Fear learning consolidation depends also on the amygdala (Phillips and LeDoux 1992; Vazdarjanova and McGaugh 1999; LeDoux 2000; Maren and Quirk 2004) that represents a possible site for aversive events'

${ }^{3}$ Corresponding author.

E-mail patrizio.blandina@unifi.it; fax 39-0554-271-280.

Article is online at http://www.learnmem.org/cgi/doi/10.1101//m.326906. memory storage (Fanselow and LeDoux 1999; Sacchetti et al. 1999; Schafe et al. 2005). Since fear memory reactivation in the amygdala is poorly understood, we examined whether the same amygdala neuronal systems underlying consolidation are also required for recalled memories to persist. Previously, we reported that amygdalar post-training inactivation through local administration of a sodium channel blocker, tetrodotoxin (TTX), impaired fear memories' consolidation (Sacchetti et al. 1999). Similar treatments with histamine $\mathrm{H}_{3}$ or muscarinic-receptor antagonists, thioperamide or scopolamine, respectively, exerted the same effects (Passani et al. 2001). Here we show the effects of similar manipulations given after retrieval. Moreover, the report that endocannabinoids underlie associative plasticity in the amygdala (Azad et al. 2004) prompted us to examine the effect of AM251, a cannabinoid receptor 1 (CB1-r) antagonist.

Experiments were done in compliance with the EU recommendations (86/609/CEE). Adult male Wistar rats (Harlan, Italy) were conditioned and tested in a Skinner box equipped with a grid floor connected to a shock-delivery apparatus (Modular Operant Cage/Grid Floor Shocker E13-08; Coulbourn Instruments) and placed in an acoustically insulated room at $20 \pm 1{ }^{\circ} \mathrm{C}$. On day 1 , rats were kept in the conditioning apparatus for $3 \mathrm{~min}$ before delivering seven electrical foot-shocks $(1 \mathrm{~mA}, 1 \mathrm{sec})$ at 30 -sec intervals. Two minutes after the foot-shock, rats were returned to their home cages. Seven days after conditioning, rats were re-exposed to the TC for 6 min without foot-shock, and behavior was recorded. Personnel blind to experimental conditions measured freezing duration, consisting of the absence of voluntary movements. Tests were performed between 10:00 and 12:00 a.m. A group of rats (Experiment 1 ) was treated immediately after training on day 1 (Fig. 1A). On day 4 , another group of rats (Experiment 2) received injections without re-exposure to the TC (Fig. 2A), whereas a third group (Experiment 3) was treated immediately after a 3-min re-exposure to the TC without footshock (Fig. 3A). Drugs, dissolved in physiological saline, were injected into the amygdala (coordinates from bregma as follows: $\mathrm{AP}=-2.8 \mathrm{~mm}, \mathrm{~L}=-4.9, \mathrm{H}=8.5$ (Paxinos and Watson 1998) of anesthetized rats (ketamine, $100 \mathrm{mg} / \mathrm{kg}$ i.p.) restrained in a stereotaxic apparatus. The injection needle (outside diameter, 0.3 $\mathrm{mm}$ ) was connected to a Hamilton syringe fixed to an electrode 


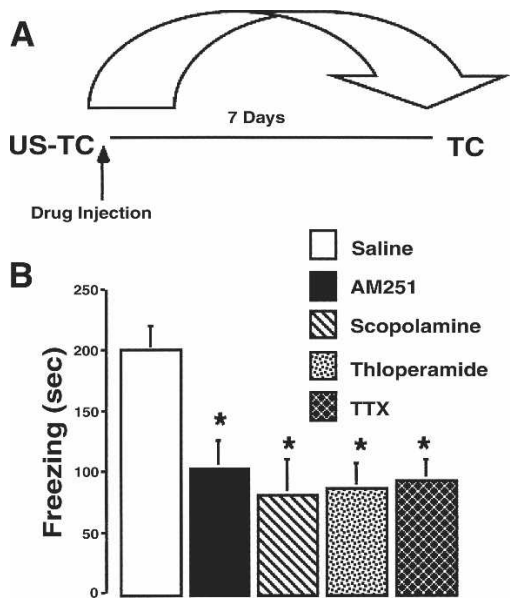

Figure 1. Effects on contextual fear conditioning of immediate posttraining bilateral injection of AM251, scopolamine, thioperamide, or TTX into the amygdala. (A) The behavioral procedure used for group 1. (B) Seven days after training, freezing was measured during the 6-min test period in saline-injected controls $(n=9)$, rats injected with $280 \mathrm{pg}$ AM251 $(n=9), 50 \mu \mathrm{g}$ scopolamine $(n=8), 44 \mathrm{pg}$ thioperamide $(n=9)$, or $5 \mathrm{ng} \operatorname{TTX}(n=10)$. Means \pm SEM are shown. ${ }^{*} P<0.05$ vs. saline (ANOVA and post hoc "All Pairs Tukey- Kramer" test).

holder. Solutions $(0.5 \mu \mathrm{L} /$ side) were injected bilaterally over a 2 -min period. The needle was withdrawn after $1 \mathrm{~min}$. Controls were injected with saline.

We previously reported that unoperated and postconditioning ketamine-anesthetized rats that received intracerebral saline injections exhibited similar freezing responses to TC (Sacchetti et al. 1999; Giovannini et al. 2003), thus suggesting that these manipulations do not interfere with consolidation. Ketamine-anesthetized animals display frequency-specific receptive field plasticity induced by Pavlovian fear conditioning (Lennartz and Weinberger 1992). Conceivably, the amnesia caused by the injected drugs are independent of ketamineinduced NMDA blocking action, although we don't know what the effects of ketamine interactions with the drugs used in this study may be. A single needle penetration appears advantageous compared with cannulation, being less traumatic (Sacchetti et al. 1999). Data from rats showing abnormal behavior (locomotor/ exploratory activities, grooming, yawning, or rearing) during the days between training and testing (7 out of 150), or with a misplaced needle $(<5 \%)$ were discarded. Placement was verified postmortem.

Statistical analysis (ANOVA followed by post hoc "All Pairs Tukey-Kramer" test) was performed using JMP IN 5 for Mac (SAS Institute, Inc.). The substances used included the following: thioperamide (RBI, Natick), tetrodotoxin (Sigma Chemical Co.), AM251 and scopolamine (Tocris Cookson Ltd.).

Experiment 1 investigated whether fear memory consolidation requires $\mathrm{CB} 1, \mathrm{H}_{3}$, or muscarinic receptor activation in the amygdala. The animals received bilateral injections of AM251 (280 pg), scopolamine (50 $\mu \mathrm{g})$, thioperamide (44 pg), or TTX (5 ng) into the amygdala immediately after conditioning (Fig. 1A). These doses are sufficient to fully block $\mathrm{CB} 1, \mathrm{H}_{3^{-}}$, muscarinicreceptors, and sodium channels, respectively (Sacchetti et al. 1999; Passani et al. 2001; Power 2004). Needle tips were positioned inside the basolateral amygdala (BLA), thus suggesting that drug effects occurred in this nucleus. However, we cannot exclude that the injections diffused also outside the BLA. Rats treated with AM251, scopolamine, thioperamide, or TTX spent significantly less time freezing in the retention test compared with controls (Fig. 1B). ANOVA revealed a main effect of group
$\left(F_{(4,44)}=5.271 ; P<0.001\right)$. The post hoc "All Pairs Tukey-Kramer" test revealed that all drug-treated groups were similar to each other, but significantly different from controls $(P<0.05)$.

Experiment 2 assessed the time window for the efficacy of the drugs investigated. Rats received intra-amygdala injections 4 $\mathrm{d}$ after training (Fig. 2A). None of the treatments altered significantly freezing duration compared with controls (ANOVA: $\left.F_{(4,45)}=0.32 ; P>0.05\right)$ (Fig. 2B).

To learn whether an established memory, when retrieved, is again sensitive to treatments that impair consolidation, a 3-min re-exposure to the TC without US was interposed on day 4 between training and testing (Fig. 3A). AM251 (280 pg), scopolamine $(50 \mu \mathrm{g})$, thioperamide (44 pg), or TTX (5 $\mathrm{ng}$ ) were injected into the rat amygdala immediately after this reactivation. $\operatorname{ANOVA}\left(F_{(4,51)}=5.582 ; P<0.001\right)$ followed by post hoc "All Pairs Tukey-Kramer" test showed that the AM251 and TTX groups froze significantly less than all other groups $(P<0.05)$ (Fig. 3B).

This report indicates that consolidated fear memories, when reactivated, are sensitive to amnesic treatments. The same treatments, in the absence of memory retrieval, leave memory intact. A growing body of evidence shows that memory is amenable to disruption when activated (Lewis 1979; Nader et al. 2000; Gruest et al. 2004). A key finding of this study is that post-training and post-retrieval administration of AM251 and TTX impair fear memory, whereas scopolamine and thioperamide disrupt only consolidation. These differences might be induced by the different protocols used, exposure to the US-TC versus exposure to the TC alone (Dudai and Eisenberg 2004; Alberini 2005; Nader et al. 2005); however, an alternative hypothesis can be offered. TTX effects indicate that neuronal activity in the amygdala is crucial for consolidation of contextual fear memory and to render this memory persistent after retrieval. Yet, the neuronal systems engaged do not completely overlap. The cannabinoid system may participate in memory consolidation and maintenance after reactivation. Conversely, cholinergic and histaminergic neurons are involved only in consolidation. This seems in conflict with the report that hemicholinium-3, a choline uptake inhibitor, impaired memory when given after a retrieval event (Boccia et al.
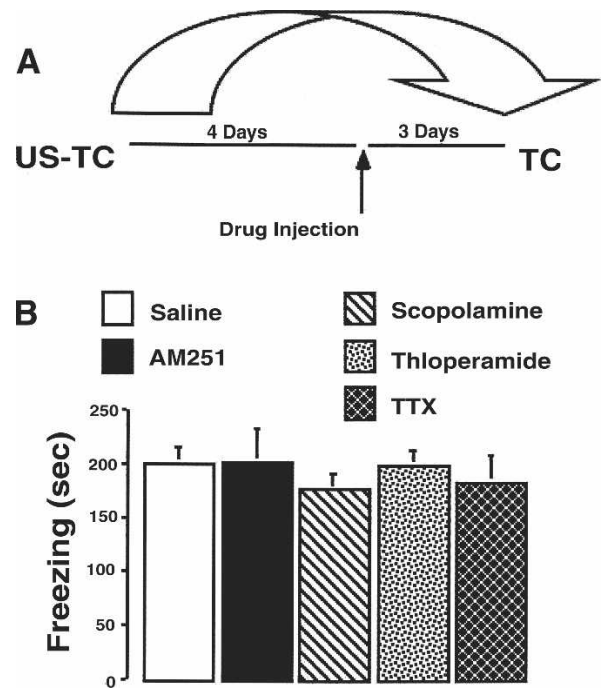

Figure 2. Effects on contextual fear conditioning of bilateral injection of AM251, scopolamine, thioperamide, or TTX into the amygdala administered $4 \mathrm{~d}$ after training. $(A)$ The behavioral procedure used for group 2 . $(B)$ Seven days after training, freezing was measured during the 6-min test period in saline-injected controls $(n=10)$, rats injected with $280 \mathrm{pg}$ AM251 $(n=8), 50 \mu \mathrm{g}$ scopolamine $(n=10), 44 \mathrm{pg}$ thioperamide $(n=9)$, or $5 \mathrm{ng} \operatorname{TTX}(n=9)$. Means \pm SEM are shown. 

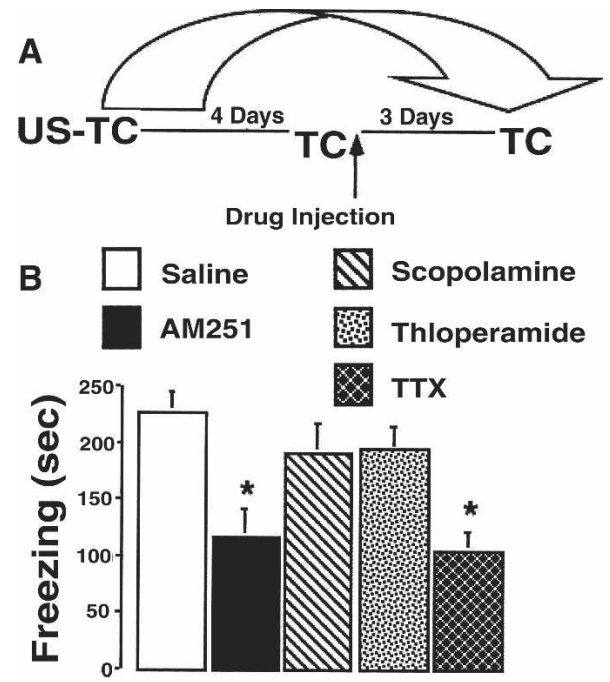

Figure 3. Effects on contextual fear conditioning of bilateral injection of AM251, scopolamine, thioperamide, or TTX into the amygdala administered $4 \mathrm{~d}$ after training and immediately after re-exposure to TC. $(A)$ The behavioral procedure used for group 3. (B) Seven days after training, freezing was measured during the 6-min test period in saline-injected controls $(n=10)$, rats injected with $280 \mathrm{pg} \mathrm{AM} 251(n=11), 50 \mu \mathrm{g} \mathrm{sco-}$ polamine $(n=11), 44 \mathrm{pg}$ thioperamide $(n=10)$, or $5 \mathrm{ng}$ TTX $(n=10)$. Means \pm SEM are shown. ${ }^{*} P<0.05$ vs. saline (ANOVA and post hoc "All Pairs Tukey-Kramer" test).

2004). Differences in the administration route, the species, and the paradigm used may account for the discrepancy. We previously reported consolidation-impairing effects of scopolamine, thioperamide, or TTX using a slightly different protocol, as freezing was measured 3 instead of $7 \mathrm{~d}$ after conditioning (Sacchetti et al. 1999; Passani et al. 2001). A critical event for aversive memory consolidation is muscarinic receptor activation within the BLA (Power 2004). $\mathrm{H}_{3}$-receptors influence fear memories by modulating acetylcholine release from the BLA (Passani et al. 2004). Indeed, intra-BLA administration of $\mathrm{H}_{3}$-receptor antagonists impaired (Passani et al. 2001), whereas administration of $\mathrm{H}_{3}$ receptor agonists ameliorated (Cangioli et al.2002) contextual fear memory consolidation. Noteworthy, BLA perfusion with $\mathrm{H}_{3}$ antagonists agonists decreased (Passani et al. 2001), whereas with $\mathrm{H}_{3}$-agonists increased (Cangioli et al. 2002) BLA acetylcholine release, at concentrations comparable to those affecting memory. Inhibitory $\mathrm{H}_{3}$-autoreceptors are likely involved, as local perfusion with thioperamide increased BLA histamine release (Cenni et al. 2004; Passani et al. 2004). Selection of drugs and doses used in the present study stems from those studies, where multiple dosages and several drugs were tested (Passani et al. 2004). The histaminergic system is part of a neural circuit activated by emotional arousal and might mediate hypothalamic influences on the BLA to achieve an adequate behavioral response (Haas and Panula 2003). Thus, the critical role of BLA in fear memory consolidation appears substantiated, as well as cholinergic and histaminergic involvements. Conversely, the impairment produced by amygdalar CB1-r blockade is a novel and unexpected finding, and contrasts with the report that administration of SR141716A, another CB1-r antagonist, failed to affect either consolidation or reactivation of contextual fear conditioning in mice (Suzuki et al. 2004). Moreover CB1-r-deficient mice showed no deficits in learning and recalling the association of a tone with a foot shock, being impaired only during extinction (Marsicano et al. 2002). Methodological differences may explain the discrepancySR141716A was given systemically and prior to conditioning (Suzuki et al. 2004), rats may respond differently than mice, and compensation mechanisms may occur in genetically modified animals. Noteworthy, CB1-r are present in the amygdala (Katona et al. 2001), where they are involved in long-term depression of GABA-mediated inhibitory currents (Marsicano et al. 2002), which fits well with our results and with reports that intra-BLA administration of GABA antagonists enhances, whereas GABA agonists disrupts fear-memory consolidation (McGaugh 2000). Furthermore, intrahippocampal injection of AM251 disrupted consolidation of an inhibitory avoidance response in rats (de Oliveira Alvares et al. 2005).

New memory consolidation is impaired by manipulations occurring within a specific time window, minutes to several hours, after learning. After this time frame, memory is unaffected (Ambrogi Lorenzini et al. 1998; Dudai and Eisenberg 2004). We assessed the time window in this study by delaying drug administration to $4 \mathrm{~d}$ after training (Fig. 2A). Under these conditions, no treatment modified freezing significantly compared with controls (Fig. 2B), thus indicating that memory became resistant to disruption. Indeed, the freezing duration of group 1 controls (Fig. 1B) and all animals of group 2 (Fig. 2B) is very similar. This observation rules out the possibility that the shorter freezing time is due to long-lasting or nonspecific effects of the drugs.

Rats injected bilaterally into the BLA with AM251 or TTX immediately after a 3-min re-exposure to TC, which was performed $4 \mathrm{~d}$ after acquisition, froze significantly less than those injected with saline, scopolamine, or thioperamide at the retention test given $3 \mathrm{~d}$ later (Fig. 3B). When learned associations are recalled from long-term memory stores by presentation of a conditioned stimulus (CS), two processes are initiated. One reactivates the association between CS and the US and transfers it from a stable to a sensitive form. The other is an extinction process in which presentation of the CS alone degrades the association between CS and US. Short re-exposures are reported to induce memory reactivation, but not extinction (Bucherelli and Tassoni 1992; von Hertzen and Giese 2005). Accordingly, freezing time of group 3 controls (Fig. 3B) was not significantly different from those of groups 1 and 2 (Figs. 1B, 2B), thus confirming that our protocols did not induce memory extinction. Since postreminder memory impairments seem to occur only when there is no extinction, this observation is crucial to validate the "reconsolidation" hypothesis itself (Eisenberg et al. 2003; Pedreira and Maldonado 2003; Power et al. 2006). The effects of post-retrieval administration of AM251 or TTX on freezing duration in the retention test given $3 \mathrm{~d}$ after the reactivation (Fig. 3) suggest that retrieved emotional memories may have to be rebuilt. These findings fit well with the "reconsolidation" hypothesis. Some caveats are, however, appropriate-3-d intervals might be too short to rule out that the observed amnesia is temporary. Moreover, performing only one post-reactivation test of retention precludes the detection of performance recovery, which might have been achieved with repeated retention testing, as shown in several reports (Lattal and Abel 2004; Power et al. 2006; Prado-Alcalá et al. 2006). Therefore, the impairment observed in this study after post-retrieval treatments might be due to temporary retrieval failure. Yet, the mismatch between neuronal circuits engaged in consolidation and reactivation is intriguing. The cannabinoid system is involved in the consolidation of contextual fear memory and its maintenance after reactivation. Conversely, cholinergic and histaminergic neurons seem to participate only in memory consolidation. Thus, this study suggests for the first time that consolidation and reactivation share some intrinsic mechanisms in the amygdala, yet reactivation is a partial recapitulation of consolidation. This hypothesis is consistent with a report of differential engagement of immediate-early genes in the mouse hippocampus after contextual fear conditioning and reactivation of the context-shock memory (von Hertzen and Giese 2005). Par- 
tial, rather than total recapitulation is a more reliable and economic way to maintain fear memory after reactivation. These observations are relevant to fundamental issues in memory research, e.g., the nature of memory persistence. It appears that the time between last activation and intervention is a crucial factor in establishing whether the acquired behavior will be obliterated. This observation may have an important implication in therapy to attenuate stubborn traumatic memories. In clinical practice, one way to overcome inappropriate panic is to expose the patient to an element of the disturbing situation (Nadel and Land 2000). Then, one might envisage the association of exposure with drug treatment to disrupt the reactivated memory. In this regard, the novel role of endocannabinoids in both consolidation and reactivation is very interesting, and might widen the applications for a CB1 antagonist soon available for human use (Wadman 2006). Disorders of emotional memory, such as phobias, post-traumatic stress, or chronic pain (Emery and Amaral 2000; Pertwee 2001; Adolphs et al. 2005) may benefit from these treatments, and this study suggests the use of CB1-r antagonists to attenuate stubborn memories.

\section{Acknowledgments}

This research was supported by FIRB (RBAU017SWS) and MURSTCOFIN (40\% and 60\%) grants.

\section{References}

Adolphs, R., Gosselin, F., Buchanan, T., Tranel, D., Schyns, P., and Damasio, A. 2005. A mechanism for impaired fear recognition after amygdala damage. Nature 433: 68-72.

Alberini, C.M. 2005. Mechanisms of memory stabilization: Are consolidation and reconsolidation similar or distinct processes? Trends Neurosci. 28: 51-56.

Ambrogi Lorenzini, C., Baldi, E., Bucherelli, C., Sacchetti, B., and Tassoni, G. 1998. Temporal characterization of subcortical nuclei in mnemonic processes: Results of tetrodotoxin reversible inactivation studies in the rat. Arch. Ital. Biol. 136: 279-296.

Azad, S.C., Monory, K., Marsicano, G., Cravatt, B.F., Lutz, B., Zieglgansberger, W., and Rammes, G. 2004. Circuitry for associative plasticity in the amygdala involves endocannabinoids signaling. $J$. Neurosci. 24: 9953-9961.

Biedenkapp, J.C. and Rudy, J.W. 2004. Context memories and reactivation: Constraints on the reconsolidation hypothesis. Behav. Neurosci. 118: 956-964.

Boccia, M.M., Acosta, G.B., Blake, M.G., and Baratti, C.M. 2004 Memory consolidation and reconsolidation of an inhibitory avoidance response in mice: Effects of i.c.v. injections of hemicholinium 3. Neuroscience 124: 735-741.

Bucherelli, C. and Tassoni, G. 1992. Engram activation reinstates the susceptibility of consolidated memory traces to retrograde amnesia by functional blockade of parabrachial nuclei. Behav. Brain Res. 51: $61-65$.

Cammarota, M., Bevilaqua, L.R., Medina, J.H., and Izquierdo, I. 2004 Retrieval does not induce reconsolidation of inhibitory avoidance memory. Learn. Mem. 11: 572-578.

Cangioli, I., Baldi, E., Mannaioni, P.F., Bucherelli, C., Blandina, P., and Passani, M.B. 2002. Activation of histaminergic H3 receptors in the rat basolateral amygdala improves expression of fear memory and enhances acetylcholine release. Eur. J. Neurosci. 16: 521-528.

Cenni, G., Cangioli, I., Yamatodani, A., Passani, M.B., Mannaioni, P.F., DiFelice, A.M., and Blandina, P. 2004. Thioperamide-elicited increase of histamine release from basolateral amygdala of freely moving rats and its therapeutic implications. Inflamm. Res. 53: S53-S54.

de Oliveira Alvares, L., Furstenau de Oliveira, L., Camboim, C., Diehl, F., Pasqualini Genro, B., Bispo Lanziotti, V., and Quillfeldt, J.A. 2005. Amnestic effect of intrahippocampal AM251, a CB1-selective blocker. in the inhibitory avoidance, but not in the open field habituation task, in rats. Neurobiol. Learn. Mem. 83: 119-124.

Dudai, Y. and Eisenberg, M. 2004. Rites of passage of the engram: Reconsolidation and the lingering consolidation hypothesis. Neuron 44: 93-100.

Eisenberg, M., Kobilo, T., Berman, D.E., and Dudai, Y. 2003. Stability of retrieved memory: Inverse correlation with trace dominance. Science 301: 1102-1104.

Emery, N. and Amaral, D. 2000. The role of the amygdala in primate social cognition. In The cognitive neuroscience of emotion (ed. R.D. Lane). Oxford University Press, UK.
Fanselow, M.S. and LeDoux, J.E. 1999. Why we think plasticity underlying Pavlovian fear conditioning occurs in the basolateral amygdala. Neuron 23: 229-232.

Giovannini, M., Efoudebe, M., Passani, M., Baldi, E., Bucherelli, C. Giachi, F., Corradetti, R., and Blandina, P. 2003. Improvement in fear memory by histamine elicited erk2 activation in hippocampal CA3 cells. J. Neurosci. 23: 9016-9023.

Gruest, N., Richer, P., and Hars, B. 2004. Memory consolidation and reconsolidation in the rat pup require protein synthesis. J. Neurosci. 24: $10488-10492$.

Haas, H. and Panula, P. 2003. The role of histamine and the tuberomamillary nucleus in the nervous system. Nat. Rev. Neurosci. 4: $121-130$.

Katona, I., Rancz, E., Acsady, L., Ledent, C., Mackie, K., Hajos, N., and Freund, T. 2001. Distribution of CB1 cannabinoid receptors in the amygdala and their role in the control of GABAergic transmission. J. Neurosci. 21: 9506-9518.

Lattal, K.M. and Abel, T. 2004. Behavioral impairments caused by injections of the protein synthesis inhibitor anisomycin after contextual retrieval reverse with time. Proc. Natl. Acad. Sci. 101: 4667-4672.

LeDoux, J.E. 2000. Emotion circuits in the brain. Annu. Rev. Neurosci. 23: $155-184$.

Lee, J., Everitt, B., and Thomas, K. 2004. Independent cellular processes for hippocampal memory consolidation and reconsolidation. Science 304: $839-843$.

Lennartz, R. and Weinberger, N. 1992. Frequency-specific receptive field plasticity in the medial geniculate body induced by Pavlovian fear conditioning is expressed in the anesthetized brain. Behav. Neurosci. 106: 484-497.

Lewis, D.J. 1979. Psychobiology of active and inactive memory. Psychol. Bull. 86: 1054-1083.

Maren, S. and Quirk, G.J. 2004. Neuronal signalling of fear memory. Nat. Rev. Neurosci. 5: 644-652.

Marsicano, G., Wotjak, C., Azad, S., Bisogno, T., Rammes, G., Cascio, M., Hermann, H., Tang, J., Hofmann, C., Zieglgansberger, W., et al. 2002. The endogenous cannabinoid system controls extinction of aversive memories. Nature 418: 530-534.

McGaugh, J.L. 2000. Memory: A century of consolidation. Science 287: $248-251$.

. 2004. Memory reconsolidation hypothesis revived but restrained: Theoretical comment on Biedenkapp and Rudy (2004). Behav. Neurosci. 118: 1140-1142.

Millin, P.M., Moody, E.W., and Riccio, D.C. 2001. Interpretations of retrograde amnesia: Old problem redux. Nat. Rev. Neurosci. 2: 68-70.

Misanin, J., Miller, R., and Lewis, D. 1968. Retrograde amnesia produced by electroconvulsive shock after reactivation of a consolidated memory trace. Science 160: 554-555.

Nadel, L. and Land, C. 2000. Memory traces revisited. Nat. Rev. Neurosci. 1: 209-212.

Nader, K. 2003. Memory traces unbound. Trends Neurosci. 26: 65-72.

Nader, K., Schafe, G.E., and LeDoux, J.E. 2000. Fear memories require protein synthesis in the amygdala for reconsolidation after retrieval. Nature 406: 722-726.

Nader, K., Hardt, O., and Wang, S.-H. 2005. Response to Alberini: Right answer, wrong question. Trends Neurosci. 28: 346-347.

Passani, M.B., Cangioli, I., Baldi, E., Bucherelli, C., Mannaioni, P.F., and Blandina, P. 2001. Histamine $\mathrm{H}_{3}$ receptor-mediated impairment of contextual fear conditioning, and in-vivo inhibition of cholinergic transmission in the rat basolateral amygdala. Eur. J. Neurosci. 14: $1522-1532$.

Passani, M.B., Lin, J.-S., Hancock, A., Crochet, S., and Blandina, P. 2004. The histamine $\mathrm{H} 3$ receptor as a novel therapeutic target for cognitive and sleep disorders. Trends Pharmacol. Sci. 25: 618-625.

Paxinos, G. and Watson, C. 1998. The rat brain in stereotaxic coordinates. Academic Press, New York.

Pedreira, M.E. and Maldonado, H. 2003. Protein synthesis subserves reconsolidation or extinction depending on reminder duration. Neuron 38: 863-869.

Pertwee, R. 2001. Cannabinoid receptors and pain. Prog. Neurobiol. 63: $569-611$.

Phillips, R.G. and LeDoux, J.E. 1992. Differential contribution of amygdala and hippocampus to cued and contextual fear conditioning. Behav. Neurosci. 106: 274-285.

Power, A.E. 2004. Muscarinic cholinergic contribution to memory consolidation: With attention to involvement of the basolateral amygdala. Curr. Med. Chem. 11: 987-996.

Power, A.E., Berlau, D.J., McGaugh, J.L., and Steward, O. 2006. Anisomycin infused into the hippocampus fails to block "reconsolidation" but impairs extinction: The role of re-exposure duration. Learn. Mem. 13: 27-34.

Prado-Alcalá, R.A., Diaz Del Guante, M.A., Garin-Aguilar, M.E., 
Diaz-Trujillo, A., Quirarte, G.L., and McGaugh, J.L. 2006. Amygdala or hippocampus inactivation after retrieval induces temporary memory deficit. Neurobiol. Learn. Mem. (in press).

Rudy, J.W., Biedenkopp, J.C., Moineau, J., and Bolding, K. 2006. Anysomycin and the reconsolidation hypothesis. Learn. Mem. 13: $1-3$.

Sacchetti, B., Ambrogi Lorenzini, C., Baldi, E., Tassoni, G., and Bucherelli, C. 1999. Auditory thalamus, dorsal hippocampus, basolateral amygdala, and perirhinal cortex role in the consolidation of conditioned freezing to context and to acoustic conditioned stimulus in the rat. J. Neurosci. 19: 9570-9578.

Sara, S.J. 2000. Retrieval and reconsolidation: Toward a neurobiology of remembering. Learn. Mem. 7: 73-84.

Schafe, G.E., Doyere, V., and LeDoux, J.E. 2005. Tracking the fear engram: The lateral amygdala is an essential locus of fear memory storage. J. Neurosci. 25: 10010-10015.

Suzuki, A., Josselyn, S., Frankland, P., Masushige, S., Silva, A., and Kida, S. 2004. Memory reconsolidation and extinction have distinct temporal and biochemical signatures. J. Neurosci. 24: 4787-4795. Vazdarjanova, A. and McGaugh, J.L. 1999. Basolateral amygdala is involved in modulating consolidation of memory for classical conditioning. J. Neurosci. 19: 6615-6622.

Vianna, M.R.M., Szapiro, G., McGaugh, J.L., Medina, J.H., and Izquierdo, I. 2001. Retrieval of memory for fear-motivated training initiates extinction requiring protein synthesis in the rat hippocampus. Proc. Natl. Acad. Sci. 98: 12251-12254.

vonHertzen, L.S.J. and Giese, K.P. 2005. Memory reconsolidation engages only a subset of immediate-early genes induced during consolidation. J. Neurosci. 25: 1935-1942.

Wadman, M. 2006. Rimonabant adds appetizing choice to slim obesity market. Nat. Med. 12: 28

Received February 23, 2006; accepted in revised form May 30, 2006.

\section{Learning \& Memory}




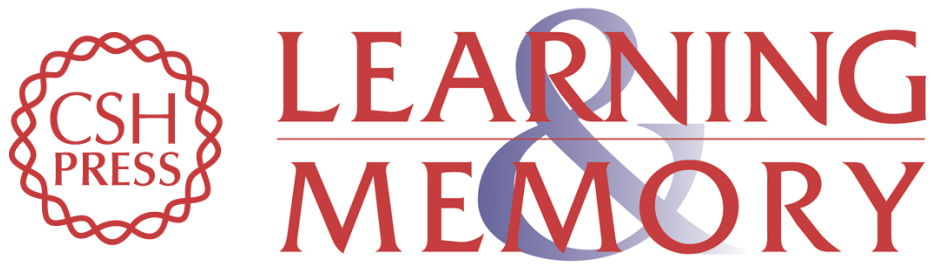

\section{Aversive memory reactivation engages in the amygdala only some neurotransmitters involved in consolidation}

Corrado Bucherelli, Elisabetta Baldi, Chiara Mariottini, et al.

Learn. Mem. 2006, 13:

Access the most recent version at doi:10.1101/lm.326906

References This article cites 49 articles, 18 of which can be accessed free at:

http://learnmem.cshlp.org/content/13/4/426.full.html\#ref-list-1

License

Email Alerting Receive free email alerts when new articles cite this article - sign up in the box at the Service top right corner of the article or click here. 